\title{
Comments on the new groin hernia guidelines: What has changed? What has remained unanswered?
}

Hakan Kulaçoğlu (D)

\section{ABSTRACT}

ORCID ID of the author: H.K. 0000-0001-7907-4587.

Cite this paper as: Kulaçoğlu H. Comments on the new groin hernia guidelines: What has changed? What has remained unanswered? Turk J Surg 2018; 34: 83-88.

Ankara Hernia Center, Ankara, Turkey

\section{Corresponding Author} Hakan Kulaçoğlu e-mail: hakankulacoglu@ hotmail.com

Received: 28.02 .2018 Accepted: 09.03.2018

CCopyright 2018 by Turkish Surgical Association Available online at www.turkjsurg.com
Guidelines are meant to evaluate the options available in the current circumstances and suggest the proper solutions for particular problems. The duty of a guideline is to present a basis for decision-making. Surgical options for the treatment of groin hernias are numerous. Recently, a joint guideline called "International Guidelines for Groin Hernia Management"was developed by five continental hernia societies, the International Endo hernia Society, and the European Association for Endoscopic Surgery. This article aimed to review the methodology, statements, and recommendations of the new guidelines and emphasized the importance of the tailored surgery for groin hernias. Spreading the guidelines may provide surgeons with an up-to-date knowledge and be useful for better outcomes in groin hernia surgery.

Keywords: Femoral, groin, guidelines, hernia, inguinal, laparoscopy

\section{INTRODUCTION}

Dictionary meaning of the word "guidelines" is a set of standards, criteria, or specifications to be used or followed while performing certain tasks (1). In Medical Sciences, guidelines are a series of suggestions that are published by official institutions or associations where independent experts exist for the managements of diseases (2). Guidelines evaluate the available options in the current circumstances and suggest the proper solutions for particular problems. They are not prescriptive or directive, but physicians who do not follow these current guidelines may have to face medico-legal issues. In other words, the responsibility of a guideline is to present a basis for decision-making (3).

The earliest example of guidelines in literature was published by the American Medical Association (AMA) to be followed in human experimentation. Twenty-two years later, the AMA Judicial Council published the Ethical Guidelines for Organ Transplantation (4). To date, there are thousands of guidelines in the archives of U.S. Department of Health and Human Services Agency for Healthcare Research and Quality (5).

Surgical options for the treatment of groin hernias are numerous. Surgeons usually select the technique that they learned from their seniors; they generally display conservatism in their practice (6). In 1993, the Royal College of Surgeons published a clinical guideline for the management of groin hernias in adults (7). Soon after, in 1995, a North American publication claimed that a consensus on hernia repair is unlikely (8). Indeed, the guideline could not initially seem to affect daily practice. There was a wide range of repair techniques and postoperative advice by consultant general surgeons (9). However, the adherence to the guideline began increasing within a decade (10). Progress may be slower in general hospitals where many surgeons works, but specific centers where hernia surgeons are employed may adapt faster (11). The first comprehensive guideline on groin hernia surgery was constituted by the European Hernia Society (EHS) in 2009 (12). Two years later, the International Endo hernia Society (IEHS) created a guideline for laparoscopic/endoscopic treatment of inguinal hernia (13). Both guidelines have raised great interest among surgeons. The EHS guidelines were updated in 2014 (14), whereas the IEHS guidelines were updated in 2015 (15). Very recently, a joint guideline called "International Guidelines for Groin Hernia Management" was developed by five continental hernia societies, IEHS, and the European Association for Endoscopic Surgery (16). This article was aimed to review this latest guideline on groin hernia surgery and analyze the differences from the previous ones.

\section{METHODOLOGIES FOR THE HERNIA GUIDELINES}

Guidelines in medical practice are mainly based on category or level of the evidences, and they present the strength of recommendations. Systematic reviews and good-quality randomized controlled trials (RCTs) provide the most valuable and reliable sources and create Level 1 evidences and Grade A recommendations, whereas expert opinions create Level 4 and Grade D recommendations (17). Groin hernia guidelines have followed the same pathway. 
Table 1. The macro structures of the hernia guidelines

\begin{tabular}{|c|c|c|c|c|c|c|}
\hline Guidelines & $\begin{array}{c}\text { Publication } \\
\text { Year }\end{array}$ & $\begin{array}{l}\text { Number of } \\
\text { Participant }\end{array}$ & $\begin{array}{l}\text { Number of } \\
\text { Chapters }\end{array}$ & $\begin{array}{l}\text { Number of } \\
\text { Statements }\end{array}$ & $\begin{array}{l}\text { Number of } \\
\text { Recommendations/ } \\
\text { Conclusions }\end{array}$ & $\begin{array}{c}\text { Number } \\
\text { Pages }\end{array}$ \\
\hline EHS & 2009 & 18 & 18 & 31 & 37 & 61 \\
\hline IEHS & 2011 & 22 & 14 & 124 & 96 & 71 \\
\hline EHS update & 2014 & 17 & - & - & 20 & 13 \\
\hline IEHS update & 2015 & 25 & 18 & 37 & 29 & 33 \\
\hline International & 2018 & 54 & 31 & 132 & 87 & 165 \\
\hline
\end{tabular}

EHS: European Hernia Society; IEHS: International Endohernia Society

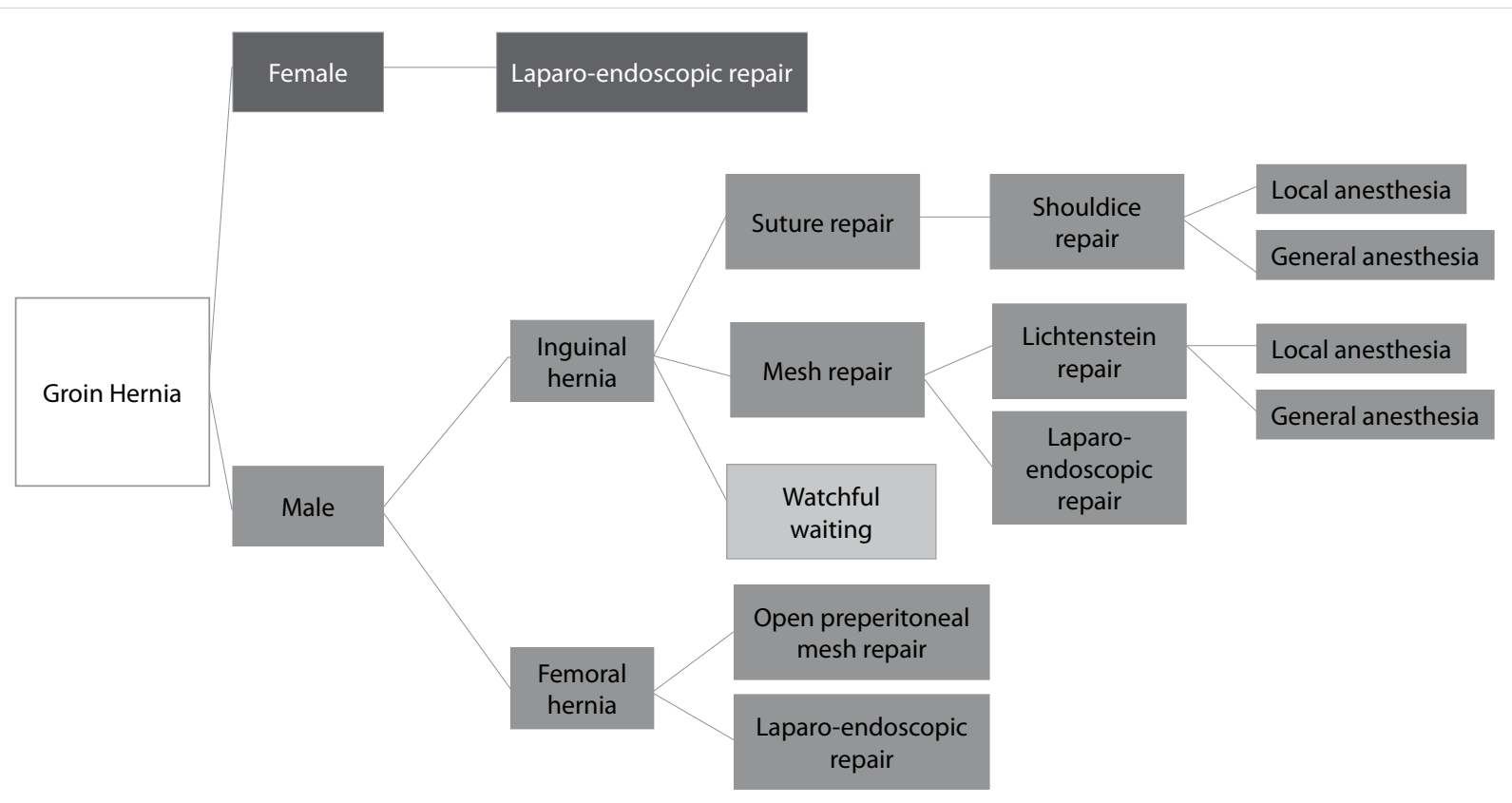

Figure 1. An algorithm for groin hernia management

The EHS guidelines were published in the journal Hernia in 2009 (12), whereas the IEHS guidelines were published in the journal Surgical Endoscopy in 2011 (13). The EHS guidelines were updated with new Level 1 studies in 2014 with 20 new conclusions (14), whereas the IEHS guidelines were updated in 2015 with 37 statements and 29 conclusions (15).

The new International Guidelines for Groin Hernia Managements has been the most comprehensive source in terms of volume (16). These guidelines were published by a group of surgeons named as "The Hernia Surge Group." For the first time, there was also an anesthesiologist pain expert. Steering Committee comprised 10 hernia surgeons. There were also 40 other members in the group. In addition, three external reviewers were assigned from three leading continents. The members scored $>3500$ published articles. Five meetings were held to complete the process. The guidelines were developed according to the AGREE Instrument II (Appraisal of Guidelines for Research and Evaluation) (18). It included the presented 132 statements and 87 recommendations in 31 chapters. Recommendations reflected not only the evidence in literature but also the view of the complete committee as
The macrostructures of five guidelines on groin hernias are given in Table 1.

\section{COMMENTS}

There are $>40$ upgraded recommendations in the new guidelines. The only downgraded recommendation is about the lower postoperative pain and reduction in chronic pain incidences after laparo-endoscopic repair of primary unilateral hernias in male patients. The evidence is considered as weak for recommendation.

Although the guidelines recommended mesh-based repairs for all inguinal hernias, Shouldice repair was also named as the choice of non-mesh repair. The true recurrence and postoperative chronic pain rates of Shouldice repair are required to be determined outside the Shouldice Hospital. Among mesh repairs, the Lichtenstein technique with a standard flat mesh still seems to be the best choice. On the other hand, laparoendoscopic repair is recommended for the repair of primary bilateral hernias. Transabdominal preperitoneal (TAPP) and totally extraperitoneal (TEP) have similar efficiencies. More importantly, the concept of tailored surgery was emphasized in the guidelines. Type of hernia, surgeon's expertise and skill, resources of the institution, and preferences of the patients are 
the factors influencing the selection of the best technique for each case (16).

There seems to be a consensus regarding groin hernias in women and femoral hernias in both genders. Laparo-endoscopic mesh repair is the best option for these conditions (18). Waiting is not recommended, and timely repair should be performed. On the other hand, day surgery is recommended for most groin hernia cases. It is best accomplished using local anesthesia. Figure 1 is produced to outline the algorithm for groin hernia in women and men according to the guidelines for groin hernia managements.

Guidelines are not legal documents or regulations, they are just recommendations. Strict adherence to guidelines is not always the case. Early studies on the effectiveness of guidelines concluded that guidelines might be unlikely to affect a rapid change in daily medical practice (19). Nevertheless, Grimshaw and Russell reviewed 59 articles published till 1990 and found that all but only four of the articles reported significant improvements after the introduction of guidelines (20).

Physicians and surgeons need to reach published guidelines to read and evaluate them before using their principles and recommendations in daily practice. Therefore, this kind of publication should be free for readers. The full text of International Guidelines for Groin Hernia Managements was available for download at www.herniasurge.com for free of cost until April 2018. Similarly, some clinical guidelines can be freely collected from the website of the official journals (21). However, the spread of each guideline may not be at the same rate. For example, a guideline for a general clinical subject such as prevention of thromboembolism has a higher chance to be visible, whereas other guidelines for specific problems in a branch of medical practice may not be as widespread. Guidelines for groin hernia management can be a typical example of the latter. Specific hernia surgeons, the followers of the international hernia meetings, and the subscribers of the hernia-related journals can meet the hernia guidelines earlier. However, groin hernia treatment is a very common procedure for almost all general surgeons, and it may be a duty of hernia surgeons to inform their colleagues about hernia guidelines.

Different institutions may create separate guidelines on the same subjects. There may be some minor or even major differences among them about the management and treatment of specific conditions $(22,23)$. Naturally, surgeons or physicians, personally or institutionally, prefer one of the recommendations in different sources. This does not seem to be the case for groin hernia guidelines. In fact, some members of the societies or associations who participated in the preparation of the newest guidelines are common. The International Guidelines for Groin Hernia Management is like a jointly updated guide book in a comprehensive way. It is a great work that provides surgeons solid recommendations on improving the outcomes of this very common surgery, although there are still some shortcomings. For example, some issues such as management of sportsman hernia were not included. This particular subject could have been evaluated as a specific aspect. The diagnosis and treatment of sportsman hernia were presented in the IEHS guidelines published in 2011 and its update in $2015(13,15)$. Therefore, one can use these publications as a good source for this subject. In addition, returning to different sports activities was not discussed in the new guidelines. Information about returning to sports and post-surgical rehabilitation can also be found in the IEHS guideline. However, discrimination among different branches of sports does not exist. Probably, the most frequently asked questions are about jogging, weightlifting, and swimming. Jogging and weightlifting are self-limited activities, and patients can drop the activity if they feel pain and discomfort, but swimming may be a safety issue regarding the risk of drowning. Therefore, surgeons and patients may need more detailed information about swimming. In fact, there is very limited published evidence about these specific subjects; therefore, it was not possible to make solid recommendations. Nonetheless an expert committee opinion would have been useful for the readers.

One of the main expectations of the surgeons from the guidelines is to find satisfying answers for the frequent questions from their patients. For example, driving after groin hernia repairs is a very common issue between surgeons and patients (24). Although the guidelines state that physical activity restriction is not necessary after uneventful repairs and that the patients can resume work and leisure activities within 3-5 days, with no increased risk of recurrence and complications, no specific recommendations are specified. In practice, advice on when to drive after groin hernia surgery may widely differ among surgeons. Ismail et al. (25) reported that recommended convalescence, by British surgeons, before patients resume driving reflected a wide spectrum from "same day as operation" to 6-8 weeks. Some verbal definitions were also used such as "as soon as you feel comfortable" or "as soon as you can do an emergency stop." A more recent survey from England also revealed that the time advised to return to driving ranged from $24 \mathrm{~h}$ to $6 \mathrm{w}$ (26). A definition of "after being able to perform an emergency stop" was also mentioned in this publication. This parameter has been studied for spine and hip operations and some qualitative measurements about braking performance $(27,28)$. Indeed, emergency stop is a safety issue, and it may be useful to advice patients about testing themselves on applying the brake sharply without starting the engine. On the other hand, automatic transmission may be advantageous and provide an early return to driving for patients undergoing a unilateral left inguinal hernia repair. It was also reported in an observational study that laparoscopic repairs could have better outcome in terms of car driving over open surgery (29). Amid, from the Lichtenstein Hernia Institute, reported that the main concern about this issue was that the inertial force of an impact or sudden stop while driving could cause recurrence because a 6- to 8-week period was needed for healing of hernia defect (30). However, as he mentioned, this is not the case in the era of tension-free open and laparo-endoscopic repairs, and patients can return to normal daily activities, including driving. Amid also agreed with Ismail et al. (25) about developing national guidelines on this issue (30).

Today, chronic pain following inguinal hernia repairs is as important an issue as recurrence. The International Guidelines evaluated this problem in detail. For the first time, a guideline addressed the genetic disposition with typing; $\mathrm{DQB} 1{ }^{*} 03: 02$ HLA haplotype is mentioned in a table on risk factors for chronic post-herniorrhaphy inguinal pain. Nevertheless, this information did not exist in the text, and the working party 
did not cite the related reference in the list. In fact, the evidence is obtained from the genetic typing study conducted by Dominguez et al. (31), which was published in 2013, and it was revealed that the DQB1 ${ }^{*} 03: 02$ HLA haplotype is associated with increased risk of chronic pain following inguinal hernia surgery.

Cancer development and carcinogenic materials are one of the main concerns of patients $(32,33)$. It is not unusual for surgeons to hear a question about the potential carcinogenic effects of hernia meshes. Furthermore, surgeons have been concerned about this frightening possibility. Being "non-carcinogenic" was included among the properties of the ideal prosthetic material (34). As mentioned in the guidelines, polymeric implants prepared as thin smooth films were possibly defined as carcinogenic to humans by The International Agency for Research on Cancer in 2000 (35). Nevertheless, the Hernia Surge Group did not find any adequate evidence about the carcinogenic potential of hernia meshes. Very recently, after the Hernia Surge meetings, Chughtai et al. (36) reported that meshbased hernia repair was not associated with an increased risk of subsequent cancer development in men. They followed 53.409 male patients with inguinal hernia and found similar cancer development rates in comparison with the control subjects who underwent cholecystectomy for cholecystitis or cholelithiasis and primary knee arthroplasty for osteoarthritis. This novel and promising study with relatively long follow-up seems to be a good instrument for addressing patients' concerns.

The International Guidelines for Groin Hernia Management scrutinized the comparison of open and laparo-endoscopic techniques and made many statements and recommendations. In fact, the evidence for laparo-endoscopic repairs has been accumulating well. These techniques are recommended for bilateral, sportsman, femoral, and groin hernias in women. However, the working party mentioned a need for designing large RCTs for better comparison in primary unilateral inguinal hernia repair in male patients by surgeons who are experts in both these techniques. It may really be required, despite two recent studies that provide more information for this comparison. In 2014, Dhankhar et al. (37) reported that Lichtenstein repair with local anesthesia is as good as TEP under general anesthesia for uncomplicated unilateral inguinal hernia. Lichtenstein repair had shorter operating time, smaller mesh size, and lower cost (37). On the other hand, a larger study by Westin et al. (38) revealed that patients operated with TEP experienced less long-term postoperative pain than those operated with the Lichtenstein technique under local anesthesia. A limitation of this study might be the randomization conducted on the day of surgery by the operating surgeon. The randomization time is relatively close to the operation hour, and it is not clear whether the patients were completely informed about the advantages of the picked technique, whereas the guidelines recommend informing the patients that "There are many different repair techniques in routine use with varying advantages and disadvantages. Your surgeon will discuss these and other issues with you." (16). It does not mean having a small conversation just before the surgery. Patel et al. (39) reported a very interesting observation that the majority of patients reported a perception that a laparoscopic repair was safer and quicker than open repair; open repair had a higher complication rate than laparoscopic treatment; laparoscopic repair had a quicker return to work; and laparoscopic repair was the only method that could be performed as a day-case procedure. It may be a consequence of some post-modern factors. It seems appropriate to create two groups where each technique is performed by its expert surgeons in its own optimal conditions: Lichtenstein repair under local anesthesia and laparo-endoscopic repair under general anesthesia. Surgeons in each group explain to their patients the advantages of the operative technique in detail with adequate time and attention. An independent monitor is included in the study; he/she may be a surgeon or an anesthesiologist with a special interest in algology. The monitor should observe the patients blindly, with no information about the operative technique used (40).

A shortcoming of the new guidelines is lack of recommendations for technical details of laparo-endoscopic procedures, whereas International Hernia Society guidelines has provided statements and recommendations about technical details and pitfalls of TAPP and TEP such as "Safest and most effective method of establishing," "Trocar choice, placement and positioning," and "How does port positioning contribute to the technique of TEP repair." (13). Surgeons and residents who need information about these specific subjects can use the IEHS guidelines as a good source.

When the first EHS guidelines were published, the authors stated that a large number of questions remained unanswered. They listed 14 questions in this subheading. Indeed, all but one question was partially or completely answered in the last guidelines. There is still one question since then that is still unanswered: "Are there non-operative options for treating an inguinal hernia?" This hope was based on the definition of hernia as a collagen disease $(41,42)$. The possible treatment modalities influencing collagen synthesis such as or other than growth factors have not been found to be promising yet. So, this is still a "question for future," possibly not for the near future.

Another "question for future" in the EHS guidelines in 2009 was about the specialization on hernia surgery and specific centers (12). Today, hernia treatment is somewhat driving through two targets: individualization of the treatment for each patient and specialization for the surgeons. The former has been defined in the guidelines as "tailored surgery," and the latter has been discussed in the new guidelines in Chapter 23: Specialized centers and hernia specialist. The working party defined a hernia specialist as "surgeon with mastery/expert-level hernia surgery skills who actively trains, educates, and performs research." The Hernia Surge Group has stated that individual case volume of a surgeon is more important than a center's case volume. Surgeon's high case volume reduces recurrence rate. More importantly, in practice, the International Guidelines for Groin Hernia Management recommends an expert hernia surgeon for the treatment of recurrent inguinal hernias, particularly after failed anterior and posterior repairs.

Antibiotic prophylaxis has always been an issue for groin hernia repairs. Guidelines and reviews do not recommend prophylaxis in elective open repairs $(12,16,43)$. However, a very recent survey from the United Kingdom stated that almost half of the surgeons used routine antibiotic prophylaxis 
(MacCormick). Interestingly, $95 \%$ of the participants in this survey believed that a new set of specific guidelines was required for this subject (44). It is recommended that antibiotic prophylaxis may be of benefit in high-risk environments, with wound infection rates of $>5 \%$ (18). Some studies from largevolume reference hospitals in Turkey reported quite high infection rates after elective inguinal hernia repairs. Yerdel et al. (45) stated that wound infection rate was $9 \%$ in patients with no prophylaxis, and this rate could be decreased to $1 \%$ with single-dose intravenous ampicillin and sulbactam. Ergul et al. (46) reported that infection rate was reduced to $5 \%$ from $7 \%$ with $1 \mathrm{~g}$ intravenous cefazolin, but the difference was not significant. They believed that antibiotic prophylaxis could not ameliorate the complex circumstances in a trauma center/general hospital (46). Institutional approaches to improve the outcomes are required to reduce infection rates in groin hernia surgery.

Lastly, it is worth mentioning that there is a striking change in Chapter 2: Risk factors for the development of inguinal hernias in adults. With low-level evidence, tobacco use is given a factor that is inversely correlated with inguinal hernia incidence. This is a contradiction to the statement in the EHS guidelines published in 2009 (12). It concluded that smokers had an increased risk of inguinal hernia. There was a recommendation for smoking cessation as the only sensible advice that could be given for preventing an inguinal hernia development. Interestingly, the cited reference for the inverse correlation of tobacco use in the International Guidelines just reported that tobacco use history increased the chance of a groin hernia diagnosis (47). This point probably needs a reasonable explanation.

\section{CONCLUSIONS}

The International Guidelines for Groin Hernia Management is the most voluminous work for treatment options for groin hernia in adults. It answers most of the questions in the surgeons mind. There is no conflict with previous guidelines, but recent information is gathered, and recommendations are produced. In general, Lichtenstein repair maintains its importance, particularly for unilateral primary inguinal hernias in men. On the other hand, laparo-endoscopic repairs have gained more support in certain conditions such as hernias in women, femoral hernias, and bilateral inguinal hernias. Spreading the guidelines may provide the surgeons with an up-to-date knowledge and may also be useful for better outcomes in groin hernia surgery.

\section{Peer-review: Externally peer-reviewed.}

Conflict of Interest: The author have no conflicts of interest to declare.

Financial Disclosure: The author declared that this study has received no financial support.

\section{REFERENCES}

1. Mosby's Medical Dictionary. 10th ed. St. Louis, MO: Mosby Elsevier, 2016.

2. Collins Dictionary of Medicine. New York: Harper-Collins Publishers, 2005.

3. Kingsnorth AN. Hunterian Lecture. Hernia surgery: from guidelines to clinical practice. Ann R Coll Surg Engl 2009; 91: 273-279. [CrossRef]

4. AMA Judical Council. Ethical guidelines for organ transplantation. JAMA 1968; 205: 341-342. [CrossRef]
5. Agency for Healthcare Research and Quaility National Guideline Clearinghouse. Avaliable from: URL: https://www.guideline.gov/ summaries/archive.

6. Seker G, Kulacoglu H. The acceptance rate of local anaesthesia for elective inguinal hernia repair among the surgeons working in a teaching hospital. J Coll Physicians Surg Pak 2012; 22: 126127.

7. The Royal College of Surgeons of England. Clinical Guidelines on the Management of Groin Hernias in Adults. London; 1993.

8. Mathias JM. Don't expect a consensus on hernia repair. OR Manager 1995; 11: 1, 6-8.

9. Boyce $D E$, Shandall $A A$, Crosby DL. Aspects of hernia surgery in Wales. Ann R Coll Surg Engl 1995; 77: 198-201.

10. Metzger J, Lutz N, Laidlaw I. Guidelines for inguinal hernia repair in everyday practice. Ann R Coll Surg Engl 2001; 83: 209-214.

11. Kulacoglu $\mathrm{H}$. Choosing repair technique for groin hernias with patients' preferences and recommendations of guidelines. Clin Surg 2017; 2: 1836.

12. Simons MP, Aufenacker T, Bay-Nielsen M, Bouillot JL, Campanelli $\mathrm{G}$, Conze J, et al. European Hernia Society guidelines on the treatment of inguinal hernia in adult patients. Hernia 2009;13: 343403. [CrossRef]

13. Bittner R, Arregui ME, Bisgaard T, Dudai M, Ferzli GS, Fitzgibbons RJ, et al. Guidelines for laparoscopic (TAPP) and endoscopic (TEP) treatment of inguinal hernia [International Endohernia Society (IEHS)]. Surg Endosc 2011; 25: 2773-2843. [CrossRef]

14. Miserez M, Peeters E, Aufenacker T, Bouillot JL, Campanelli G, Conze J, et al. Update with level 1 studies of the European Hernia Society guidelines on the treatment of inguinal hernia in adult patients. Hernia 2014; 18: 151-163. [CrossRef]

15. Bittner R, Montgomery MA, Arregui E, Bansal V, Bingener J, Bisgaard T, et al. Update of guidelines on laparoscopic (TAPP) and endoscopic (TEP) treatment of inguinal hernia (International Endohernia Society). Surg Endosc 2015; 29: 289-321. [CrossRef]

16. HerniaSurge Group. International guidelines for groin hernia management. Hernia 2018; 22: 1-165. [CrossRef]

17. Shekelle PG, Woolf SH, Eccles M, Grimshaw J. Clinical guidelines: developing guidelines. BMJ 1999; 318: 593-596. [CrossRef]

18. Brouwers M, Kho ME, Browman GP, Burgers JS, Cluzeau F, Feder G, et al. for the AGREE Next Steps Consortium. AGREE II: Advancing guideline development, reporting and evaluation in healthcare. CMAJ 2010; 182: E839-842. [CrossRef]

19. Lomas J, Anderson GM, Domnick-Pierre K, Vayda E, Enkin MW, Hannah WJ. Do practice guidelines guide practice? The effect of a consensus statement on the practice of physicians. N Engl J Med 1989; 321: 1306-1311. [CrossRef]

20. Grimshaw JM, Russell IT. Effect of clinical guidelines on medical practice: a systematic review of rigorous evaluations. Lancet 1993; 342: 1317-1322. [CrossRef]

21. Holbrook A, Schulman S, Witt DM, Vandvik PO, Fish J, Kovacs MJ, et al. Evidence-based management of anticoagulant therapy: Antithrombotic Therapy and Prevention of Thrombosis, 9th ed: American College of Chest Physicians Evidence-Based Clinical Practice Guidelines. Chest 2012; 141(2 Suppl): e152S-e184S.

22. Shanson D. New British and American guidelines for the antibiotic prophylaxis of infective

23. Nabhan F, Ringel MD. Thyroid nodules and cancer management guidelines: comparisons and controversies. Endocr Relat Cancer 2017; 24: R13-R26. [CrossRef]

24. Nunez VA, Giddins GEB. 'Doctor, when can I drive?': an update on the medico-legal aspects of driving following an injury or operation. Injury 2004; 35: 888-890. [CrossRef]

25. Ismail W, Taylor SJ, Beddow E. Advice on driving after groin hernia surgery in the United Kingdom: questionnaire survey. BMJ 2000; 321: 1056. [CrossRef]

26. Grewal P. Survey of post-operative instructions after inguinal hernia repair in England in 2012. Hernia 2014; 18: 269-272. [CrossRef] 
27. Hofmann UK, Thumm S, Jordan M, Walter C, Rondak IC, Ipach I. The effects of hip and spine orthoses on braking parameters: a simulated study with healthy subjects. PM R 2016; 8: 35-44. [CrossRef]

28. Hofmann UK, Wittmann S, Fischer AN, Jordan M, Feierabend MM, Rondak IC, et al. Influence of spine surgery on the ability to perform an emergency stop while driving a car. J Back Musculoskelet Rehabil 2018; 31: 29-36. [CrossRef]

29. Lukaszczyk JJ, Preletz RJ, Morrow GJ, Lange MK, Tachovsky TJ, Krall JM. Laparoscopic herniorrhaphy versus traditional open repair at a community hospital. J Laparoendosc Surg 1996; 6: 203208. [CrossRef]

30. Amid PK. Driving after repair of groin hernia. BMJ 2000; 321: 1033-1034. [CrossRef]

31. Dominguez CA, Kalliomäki M, Gunnarsson U, Moen A, Sandblom G, Kockum I, et al. The DQB1 *03:02 HLA haplotype is associated with increased risk of chronic pain after inguinal hernia surgery and lumbar disc herniation. Pain 2013; 154: 427-433. [CrossRef]

32. Vrinten C, van Jaarsveld CH, Waller J, von Wagner C, Wardle J. The structure and demographic correlates of cancer fear. BMC Cancer 2014; 14-597. [CrossRef]

33. Berman SH, Wandersman A. Fear of cancer and knowledge of cancer: a review and proposed relevance to hazardous waste sites. Soc Sci Med 1990; 31: 81-90. [CrossRef]

34. De Bord JR. The historical development of prosthetics in hernia surgery. Surg Clin North Am 1998; 78: 973-1006. [CrossRef]

35. No authors listed. Surgical implants and other foreign bodies. IARC Monogr Eval Carcinog Risks Hum 1999; 74: i-xi, 1-409.

36. Chughtai B, Sedrakyan A, Thomas D, Mao J, Eilber KS, Clemens JQ, et al. No increased risk of carcinogenesis with mesh-based hernia repairs. Am J Surg 2017; pii: S0002-9610(17)31404-6.

37. Dhankhar DS, Sharma N, Mishra T, Kaur N, Singh S, Gupta S. Totally extraperitoneal repair under general anesthesia versus Lichtenstein repair under local anesthesia for unilateral inguinal hernia: a prospective randomized controlled trial. Surg Endosc
2014; 28: 996-1002. [CrossRef]

38. Westin L, Wollert S, Ljungdahl M, Sandblom G, Gunnarsson U, Dahlstrand U. Less pain 1 year after total extra-peritoneal repair compared with Lichtenstein using local anesthesia: data from a randomized controlled clinical trial. Ann Surg 2016; 263: 240243. [CrossRef]

39. Patel M, Garcea G, Fairhurst K, Dennison AR. Patient perception of laparoscopic versus open mesh repair of inguinal hernia, the hard sell. Hernia 2012; 16: 411-415. [CrossRef]

40. Kulacoglu $\mathrm{H}$. What is the real fair study model to compare open and laparoscopic mesh repairs for unilateral inguinal hernia regarding postoperative pain and discomfort? MOJ Surg 2017; 4: 00062. [CrossRef]

41. Wagh PV, Leverich AP, Sun CN, White HJ, Read RC. Direct inguinal herniation in men: a disease of collagen. J Surg Res 1974; 17: 425433. [CrossRef]

42. Read RC. Inguinal herniation in the adult, defect or disease: a surgeon's odyssey. Hernia 2004; 8: 296-299. [CrossRef]

43. Erdas E, Medas F, Pisano G, Nicolosi A, Calò PG. Antibiotic prophylaxis for open mesh repair of groin hernia: systematic review and meta-analysis. Hernia 2016; 20: 765-776. [CrossRef]

44. MacCormick AP, Akoh JA. Survey of Surgeons Regarding Prophylactic Antibiotic use in inguinal hernia repair. Scand J Surg 2018: 1457496917748229. [CrossRef]

45. Yerdel MA, Akin EB, Dolalan S, Turkcapar AG, Pehlivan M, Gecim $\mathrm{IE}$, Kuterdem E. Effect of single-dose prophylactic ampicillin and sulbactam on wound infection after tension-free inguinal hernia repair with polypropylene mesh: the randomized, double-blind, prospective trial. Ann Surg 2001; 233: 26-33. [CrossRef]

46. Ergul Z, Akinci M, Ugurlu C, Kulacoglu H, Yilmaz KB. Prophylactic antibiotic use in elective inguinal hernioplasty in a trauma center. Hernia 2012; 16: 145-151. [CrossRef]

47. Ravanbakhsh $S$, Batech M, Tejirian T. Increasing Body mass index is inversely related to groin hernias. Am Surg 2015; 81: 10431046. 